\title{
Aclimatação ao estresse salino em plantas de arroz induzida pelo pré-tratamento $\mathrm{com} \mathrm{H}_{2} \mathrm{O}_{2}$
}

\author{
Fabricio E. L. Carvalho ${ }^{1}$, Ana K. M. Lobo ${ }^{1}$, Aurenivia Bonifacio ${ }^{1}$, Marcio O. Martins ${ }^{1}$, \\ Milton C. Lima N eto ${ }^{1} \&$ Joaquim A. G. Silveira ${ }^{1}$
}

\begin{abstract}
RESUMO
Estudou-se 0 efeito da aplicação exógena de peróxido de hidrogênio $\left(\mathrm{H}_{2} \mathrm{O}_{2}\right)$ na aclimatação ao estresse salino com base nas alterações fotossintéticas, indicadores de estresse oxidativo e atividade de enzimas antioxidativas em folhas de plantas de arroz. Utilizaram-se duas diferentes concentrações de $\mathrm{H}_{2} \mathrm{O}_{2}(1 \mathrm{e}$ $10 \mu \mathrm{M})$ para o pré-tratamento, concentrações essas aplicadas na solução nutritiva dois dias antes da indução do estresse salino $(100 \mathrm{mM}$ de $\mathrm{NaCl})$. A limitação fotossintética e estomática resultante da exposição ao $\mathrm{NaCl}$ foi amenizada quando as plantas foram pré-tratadas com $1 \mu \mathrm{M}$ de $\mathrm{H}_{2} \mathrm{O}_{2}$. Plantas expostas ao pré-tratamento com $\mathrm{H}_{2} \mathrm{O}_{2}$ e expostas ao $\mathrm{NaCl}$ apresentaram dano de membrana menor quando comparadas com as plantas submetidas ao $\mathrm{NaCl}$ isoladamente. $\mathrm{O}$ conteúdo de TBARS e $\mathrm{H}_{2} \mathrm{O}_{2}$ foi reduzido sensivelmente nas plantas pré-tratadas com $1 \mu \mathrm{M}$ de $\mathrm{H}_{2} \mathrm{O}_{2}$ e expostas ao $\mathrm{NaCl}$ em relação às que não foram pré-tratadas. $\mathrm{O}$ sistema antioxidativo enzimático nas plantas expostas ao $\mathrm{N} \mathrm{aCl}$ foi induzido principalmente quando ocorreu o pré-tratamento com $1 \mu \mathrm{M}$ de $\mathrm{H}_{2} \mathrm{O}_{2}$. $\mathrm{Os}$ dados sugerem que exposição prévia ao $\mathrm{H}_{2} \mathrm{O}_{2}$, pode resultar numa aclimatação mais efetiva às condições de estresse salino.
\end{abstract}

Palavras-chave: peróxido de hidrogênio, estresse oxidativo, salinidade

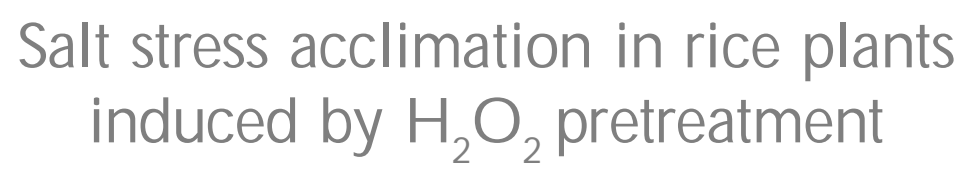

\begin{abstract}
The effect of exogenous application of hydrogen peroxide $\left(\mathrm{H}_{2} \mathrm{O}_{2}\right)$ in the acclimation to salt stress was studied on the basis of photosynthetic changes, indicators of oxidative stress and activity of antioxidant enzymes in leaves of rice plants. Two different concentrations of the $\mathrm{H}_{2} \mathrm{O}_{2}(1$ and $10 \mu \mathrm{M})$ were used for the pre-treatment, these concentrations were applied in the nutrient solution two days before the induction of salt stress $(100 \mathrm{mM} \mathrm{NaCl})$. The photosynthetic and stomatal limitations after exposure to $\mathrm{NaCl}$ were al leviated when the plants were pretreated with $1 \mu \mathrm{M} \mathrm{H}_{2} \mathrm{O}_{2}$. Plants pretreated with $\mathrm{H}_{2} \mathrm{O}_{2}$ and submitted to salt stress showed membrane damage lower in compared to plants exposed to $\mathrm{NaCl}$ alone. TBARS and $\mathrm{H}_{2} \mathrm{O}_{2}$ content was reduced appreciable in plants pretreated with $1 \mu \mathrm{M} \mathrm{H} \mathrm{H}_{2} \mathrm{O}_{2}$ and exposed to $\mathrm{NaCl}$ in relation to not pretreated. The enzymatic antioxidative system in plants exposed to $\mathrm{N} \mathrm{aCl}$ was mainly induced when there was the $1 \mu \mathrm{M} \mathrm{H}_{2} \mathrm{O}_{2}$ pretreatment. Data suggest that an anticipated exposure to $\mathrm{H}_{2} \mathrm{O}_{2}$ may result in more effective acclimation to salt stress.
\end{abstract}

Key words: hydrogen peroxide, oxidative stress, salinity

Trabalho submetido e selecionado no primeiro Simpósio Brasileiro de Salinidade realizado de 12-15/10/2010 em Fortaleza, Ceará, Brasil ${ }^{1}$ D BBM/UFC, Av. Humberto Monte, s/n, Campus do Pici, C. P. 6020, CEP 60451-970, Fortaleza, CE. Fone: (85) 3366-9821. E-mail: fabricioeulalio@hotmail.com; karlamlobo@gmail.com; aureniviablima@hotmail.com; momartins@yahoo.com.br; miltoncostalima@hotmail.com; silveira@ufc.br 


\section{INTRODUÇÃO}

De modo geral, as plantas estão, adaptadas a conviverem com certos níveis de espécies reativas de oxigênio (EROs), porém seu acúmulo nos tecidos pode levar à toxicidade e resultar na morte celular (Forman et al., 2010). As EROs são formas reduzidas do oxigênio molecular extremamente reativas, que incluem o ânion superóxido $\left(\mathrm{O}_{2}^{*}\right)$, peróxido de hidrogênio $\left(\mathrm{H}_{2} \mathrm{O}_{2}\right)$, radical hidroxílico $\left({ }^{\circ} \mathrm{OH}\right)$ e oxigênio singleto $\left({ }^{1} \mathrm{O}_{2}\right)$, e estão presentes na célula vegetal como subprodutos normais do metabolismo aeróbico e de processos fotoxidativos (Arora et al., 2002; Mittler, 2002), sendo produzidas em diferentes compartimentos celulares, tais como cloroplastos, mitocôndrias, membrana plasmática, peroxissomos, entre outros (Apel \& Hirt, 2004; Camp et al., 2004).

As plantas evoluíram um complexo sistema antioxidante para conter os efeitos deletérios das EROs (El-Shabrawi et al., 2010). Condições ambientais estressantes, tais como déficit hídrico, salinidade e calor, causam desbalanço entre produção e remoção das EROs; assim, o saldo final pode ser uma elevação dos níveis de EROs e, consequentemente, o estresse oxidativo, que leva à redução na produtividade dos vegetais (Vaidyanathan et al., 2003; Guo et al., 2006). As EROs produzidas em qualquer compartimento celular, são controladas por um sistema antioxidante que atua de forma coordenada e é composto pelo ciclo ascorbato-glutationa que inclui um grande número de compostos antioxidantes hidrofílicos, como o ácido ascórbico (ASA) e a glutationa (GSH), e ainda enzimas antioxidantes, das quais as mais importantes são as dismutases de superóxido (SOD), catalases (CAT) e peroxidases de ascorbato (APX) (Miller et al., 2008; 2010).

Apesar do papel deletério que tem sido atribuído a grande parte das EROs, alguns autores defendem o papel de sinalizador molecular das condições ambientais, em particular ao peróxido de hidrogênio $\left(\mathrm{H}_{2} \mathrm{O}_{2}\right)$ (Mittler, 2002; Xiong et al., 2002; Miller et al., 2008). $\mathrm{O} \mathrm{H}_{2} \mathrm{O}_{2}$ pode ser removido pelas CAT e APX através de diferentes mecanismos que resultam, igualmente, em água (Mittler, 2002; Foyer \& Noctor, 2003). Quando o $\mathrm{H}_{2} \mathrm{O}_{2}$ é produzido nos cloroplastos, este é eliminado pelas enzimas APX, enquanto aquele produzido nos peroxissomos/ glioxissomos é removido pelas CAT (Mittler et al., 2004; Kotchoni \& Gachomo, 2006). Esta especificidade entre as enzimas e $\mathrm{H}_{2} \mathrm{O}_{2}$ reflete suas diferentes afinidades, em que a APX teria alta afinidade $(\mu \mathrm{M})$ e a CAT baixa afinidade $(\mathrm{mM})$ pelo $\mathrm{H}_{2} \mathrm{O}_{2}$. Assim, as APX seriam responsáveis pela modulação fina dessas EROs, enquanto as CAT seriam responsáveis pela remoção do excesso de EROs durante o estresse. Desta forma, a CAT e APX apresentam extrema importância na célula vegetal e foco significativo em estudos que visam compreender suas interações sob os diferentes tipos de estresses ambientais (Shigeoka et al., 2002; Foyer \& Noctor, 2003).

A alta concentração de EROs pode causar alterações no metabolismo vegetal, devido a uma restrição dos processos fotossintéticos (Cattivelli et al., 2008). Sob condições de estresse, tais como seca, salinidade e/ou calor, a fotossíntese é um dos processos do metabolismo vegetal que podem ser primariamente afetados, tanto de forma direta, através da restrição estomática e, consequentemente, baixa disponibilidade de $\mathrm{CO}_{2}$, ou de forma indireta, pelo desbalanço entre a produção e a remoção de EROs produzidas durante o processo fotossintético - principalmente $\mathrm{o}_{2} \mathrm{O}_{2}$ - que culminam no estresse oxidativo (Møller et al., 2007; Chaves et al., 2009).

Embora exista um crescente interesse em compreender os processos envolvidos na resposta ao estresse oxidativo, ainda não é possível afirmar quais são os níveis críticos de EROs , principalmente do $\mathrm{H}_{2} \mathrm{O}_{2}$, que levam à sinalização ou dano oxidativo (Miller et al., 2010). Assim, o presente estudo teve por objetivo verificar se a pré-exposição de plantas de arroz ao $\mathrm{H}_{2} \mathrm{O}_{2}$ resultaria numa resposta mais efetiva às condições de estresse salino.

\section{Material E MÉTODOS}

\section{Obtenção do material vegetal e condições experimentais}

Sementes de arroz (Oryza sativa spp. japonnica; cultivar Nipponbare) foram semeadas em papel Germitest ${ }^{\circledR}$ após serem desinfetadas com $\mathrm{NaClO} 1,5 \%$ (v/v) durante $10 \mathrm{~min}$ sob agitação eventual, lavadas três vezes e embebidas, por $20 \mathrm{~min}$, em água deionizada. As sementes foram mantidas em condições controladas $\left(240 \mu \mathrm{mol} \mathrm{m}^{-2} \mathrm{~s}^{-1} ; 25 \pm 2{ }^{\circ} \mathrm{C} ; 70 \% \mathrm{UR}\right.$; fotoperíodo de $12 \mathrm{~h}$ ) por oito dias. Ao final dos oito dias, as plântulas de arroz foram transferidas para vasos de 2,0 L que continham solução nutritiva de Hoagland \& Arnon diluída 1:4 (pH 6,0 \pm 0,2 ) e após uma semana a solução nutritiva foi trocada para 1:2 e mantida até o final do período experimental.

Após o período de aclimatação as plantas foram pré-tratadas com 0,1 e $10 \mu \mathrm{M}$ de peróxido de hidrogênio $\left(\mathrm{H}_{2} \mathrm{O}_{2}\right)$, enquanto não expostas ao $\mathrm{H}_{2} \mathrm{O}_{2}(0)$ foram tomadas como tratamento controle. $\mathrm{O} \mathrm{H}_{2} \mathrm{O}_{2}$ foi aplicado na solução nutritiva e as plantas permaneceram com as raízes imersas na solução contendo $\mathrm{H}_{2} \mathrm{O}_{2}$ por $24 \mathrm{~h}$. Ao final deste período a solução nutritiva foi trocada e um grupo de plantas recebeu $100 \mathrm{mM}$ de $\mathrm{NaCl}$ na solução nutritiva, de forma parcelada, e em outro grupo o $\mathrm{NaCl}$ não foi aplicado. Ao final da diferenciação dos tratamentos, as plantas foram transferidas para câmara de crescimento e mantidas em condições controladas $\left(400 \mu \mathrm{mol} \mathrm{m}{ }^{-2} \mathrm{~s}^{-1} ; 25 \pm 2{ }^{\circ} \mathrm{C} ; 80 \% \mathrm{UR}\right.$; fotoperíodo de $12 \mathrm{~h}$ ).

Durante o período experimental foram realizadas, em plantas com 30 dias, medidas de fotossíntese e condutância estomática com auxílio do IRGA (Infrared Gas Analyzer; LCI System/ADC BioScientific) e, ao final deste período, seguimentos foliares foram coletados com vistas determinação do dano de membrana; enfim, amostras vegetais foliares foram congeladas em $\mathrm{N}_{2}$ líquido e armazenadas em freezer $-80^{\circ} \mathrm{C}$, até o momento das análises.

\section{Determinação do dano de membrana}

O dano de membrana (DM) foi calculado com base no vazamento de íons potássio seguindo-se a metodologia descrita adiante. Cerca de 20 segmentos foliares foram pesados, transferidos para tubos e imersos em água destilada onde ficaram por $24 \mathrm{~h}$ em constante agitação; em seguida, mensurou-se a concentração de potássio na solução (L1) através do fotômetro de emissão de chama (Micronal, modelo B462) e então os tubos 
foram levados ao banho-maria por $1 \mathrm{~h}$ a $95{ }^{\circ} \mathrm{C}$; posteriormente, com a solução em temperatura ambiente, a concentração de potássio na solução foi novamente mensurada (L2); o DM foi calculado pela seguinte equação: $\mathrm{DM}=(\mathrm{L} 1 / \mathrm{L} 2)$ x $100(\%)$.

\section{Determinação do conteúdo de peróxido de hidrogênio $\left(\mathrm{H}_{2} \mathrm{O}_{2}\right)$}

O método utilizado foi semelhante ao descrito por Brennan \& Frenkel (1977) com algumas modificações. Cerca de 100 mg de tecido fresco de folhas de arroz foi pesado e macerado na presença de $\mathrm{N}_{2}$ líquido até obtenção de farinha homogênea; a esta farinha se adicionou $1,0 \mathrm{~mL}$ de TCA $5 \%$ e a maceração foi continuada por $3 \mathrm{~min}$. As amostras foram centrifugadas a 10.000 g por 5 min a $4{ }^{\circ} \mathrm{C}$, o sobrenadante coletado e o precipitado descartado; do sobrenadante; foram recolhidas alíquotas de $100 \mu \mathrm{L}$ que, depois de diluídas, foram misturadas com $\mathrm{TiCl}_{4}$ $20 \%$ em $\mathrm{HCl} 11 \mathrm{mM}(\mathrm{v} / \mathrm{v})$ e $\mathrm{NH}_{4} \mathrm{OH}$; após uma série de centrifugações a $10.000 \mathrm{~g}$ por $5 \mathrm{~min}$ a $4{ }^{\circ} \mathrm{C}$ e lavagens do precipitado, este foi ressuspendido em $\mathrm{H}_{2} \mathrm{SO}_{4} 1,0 \mathrm{M}$ e TCA $5 \%$ e o volume final lido em espectrofotômetro a $415 \mathrm{~nm}$; as concentrações de $\mathrm{H}_{2} \mathrm{O}_{2}$ foram obtidas a partir de curva padrão

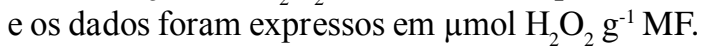

\section{Peroxidação de lipídeos}

O método de determinação da peroxidação de lipídeos se baseia no proposto por Heath \& Packer (1968). Aproximadamente $200 \mathrm{mg}$ de folhas frescas foram macerados em almofariz, na presença de $\mathrm{N}_{2}$ líquido e, em seguida, adicionado $1,5 \mathrm{~mL}$ de TCA $5 \%$ e a maceração continuada por mais $3 \mathrm{~min}$; o extrato foi centrifugado a $13.000 \mathrm{~g}$ durante $15 \mathrm{~min}$ a $4{ }^{\circ} \mathrm{C}$ e, posteriormente, $500 \mu \mathrm{L}$ do sobrenadante foram adicionados a 2,0 mL da solução TCA $20 \%$ e TBA $0,5 \%$ (p/v) e aquecidos em banho-maria a $100{ }^{\circ} \mathrm{C}$ em tubos hermeticamente fechados, durante $1 \mathrm{~h}$; ao final, a reação foi interrompida em banho de gelo e as leituras realizadas a 532 e 660 nm. O conteúdo de substâncias reativas ao ácido tiobarbitúrico (TBARS) foi estimado pelo uso do coeficiente de extinção molar de $155 \mathrm{mM}^{-1}$ $\mathrm{cm}^{-1}$, após a subtração da absorbância obtida a $660 \mathrm{~nm}$ daquela a $532 \mathrm{çm}$. Os dados de TBARS foram expressos em nmol TBA$\mathrm{MDA} \mathrm{g}^{-1} \mathrm{MF}$.

\section{Preparo do extrato enzimático}

Para o preparo do extrato enzimático, tampão fosfato de potássio $100 \mathrm{mM}(\mathrm{pH} 7,0)$, adicionado de EDTA $1 \mathrm{mM}$ e ácido ascórbico $1 \mathrm{mM}$, foi homogeneizado com $200 \mathrm{mg}$ de massa fresca foliar previamente macerada com $\mathrm{N}_{2}$ líquido, em almofariz e pistilo (Zimmermam et al., 2006). Após centrifugação a 14.000 g por 25 min a $4^{\circ} \mathrm{C}$, o sobrenadante foi recolhido e utilizado na determinação da atividade das enzimas Catalase (CAT), Peroxidase do ascorbato (APX) e Dismutase do superóxido (SOD).

\section{Determinação das atividades enzimáticas}

A determinação de CAT (EC 1.11.1.6) foi realizada como descrito por Havir \& McHale (1987). Alíquotas de extrato enzimático foram adicionadas ao tampão fosfato de potássio $50 \mathrm{mM}(\mathrm{pH} 7,0)$ contendo peróxido de hidrogênio $\left(\mathrm{H}_{2} \mathrm{O}_{2}\right) 20$ $\mathrm{mM}$ a $30{ }^{\circ} \mathrm{C}$ e o decaimento da absorbância a $240 \mathrm{~nm}$ foi acompanhado durante 300 segundos, com leituras a cada 30 segundos. A atividade da enzima foi, então, calculada com base no coeficiente de extinção molar do $\mathrm{H}_{2} \mathrm{O}_{2}$ de $36 \mathrm{mM}^{-1} \mathrm{~cm}^{-1}$ a 240 nm e expressa em $\mu$ mol $\mathrm{H}_{2} \mathrm{O}_{2} \mathrm{~g}^{-1} \mathrm{MF}$ min $^{-1}$.

Determinou-se a atividade de APX (EC 1.11.1.1) utilizandose o método descrito por Nakano \& Asada (1981), quando alíquotas do extrato enzimático foram então misturadas ao tampão fosfato de potássio $50 \mathrm{mM}(\mathrm{pH} \mathrm{6,0)}$ contendo ascorbato (AsA) 0,5 mM; a reação foi iniciada com a adição de $\mathrm{H}_{2} \mathrm{O}_{2} 30$ mM e o decaimento da absorbância a $290 \mathrm{~nm}$ foi monitorado durante 300 segundos, com leitura em intervalos de 30 segundos. $\mathrm{O}$ cálculo da atividade de APX foi feito com base no coeficiente de extinção molar de $2,8 \mathrm{mM}^{-1} \mathrm{~cm}^{-1}$ para o AsA a $290 \mathrm{~nm}$ e expressa como $\mu \mathrm{mol} \mathrm{AsA} \mathrm{g} \mathrm{g} \mathrm{MF} \mathrm{min}^{-1}$.

A atividade da SOD (EC 1.15.1.1) foi mensurada com base na inibição da redução do NBT (p-nitro blue tetrazolium) pelo extrato enzimático (Beauchamp \& Fridovich, 1971; Giannopolitis \& Ries, 1977). Alíquotas do extrato enzimático foram transferidas para tubos de ensaio protegidos da luz, contendo tampão fosfato de potássio $50 \mathrm{mM}(\mathrm{pH} \mathrm{7,8)}$ adicionado de EDTA 0,1 mM, L-metionina $13 \mathrm{mM}$ e NBT 75 $\mu \mathrm{M}$. A reação foi iniciada pela adição de $2 \mu \mathrm{M}$ de riboflavina e a concomitante transferência dos tubos para uma câmara iluminada por lâmpada de 30 Watts, durante o tempo de 5 min; em seguida, ao meio de reação foi lido em espectrofotômetro a $560 \mathrm{~nm}$. Uma unidade de atividade de SOD (U) foi definida como a quantidade de enzima necessária para inibir $50 \%$ da redução do NBT e a atividade foi expressa em $\mathrm{U} \mathrm{g}^{-1} \mathrm{MF} \min ^{-1}$.

\section{Delineamento experimental e análise estatística}

O delineamento experimental foi o inteiramente casualizado, com um fatorial de $2 \times 3$ [dois níveis de $\mathrm{NaCl}(0$ e $100 \mathrm{mM})$ e três diferentes níveis de $\mathrm{H}_{2} \mathrm{O}_{2}(0,1$ e $\left.10 \mu \mathrm{M})\right]$ com quatro repetições. Cada repetição foi formada de um vaso, que continha quatro plantas. A análise dos dados foi realizada através do programa ASSISTAT procedendo-se à análise de variância e a aplicação do teste de Tukey a 5\% de probabilidade, para comparação das médias.

\section{RESULTADOS E DISCUSSÃO}

As situações de estresses ambientais, dentre eles a salinidade limitam, em todo mundo, o desenvolvimento das espécies vegetais (Xiong \& Zhu, 2001), sendo que o excesso de sais na superfície do solo pode afetar bastante o crescimento das plantas (Munns \& Tester, 2008). Durante o estresse salino todos os principais processos metabólicos realizados pelas espécies vegetais, principalmente a fotossíntese, são afetados e, consequentemente, ocorre uma redução da taxa de expansão da superfície foliar que é agravada a partir do momento em que o estresse se intensifica (Mahajan \& Tuteja, 2005).

Registrou-se, em nosso estudo, redução significativa na taxa fotossintética nas plantas expostas ao $\mathrm{NaCl}$ isolado, na ordem de 35\% em relação ao tratamento controle (Figura 1A). Quando as plantas sofreram pré-tratamento com $1 \mu \mathrm{M}$ de $\mathrm{H}_{2} \mathrm{O}_{2}$ esta redução na fotossíntese foi de $28 \%$ quando foi comparada com o seu respectivo controle. As plantas pré-tratadas com 10 $\mu \mathrm{M}$ de $\mathrm{H}_{2} \mathrm{O}_{2}$ e posteriormente submetidas a $100 \mathrm{mM}$ de $\mathrm{NaCl}$, 
sofreram reduções superiores a $30 \%$ na taxa fotossintética em comparação com as plantas controle (Figura 1A).

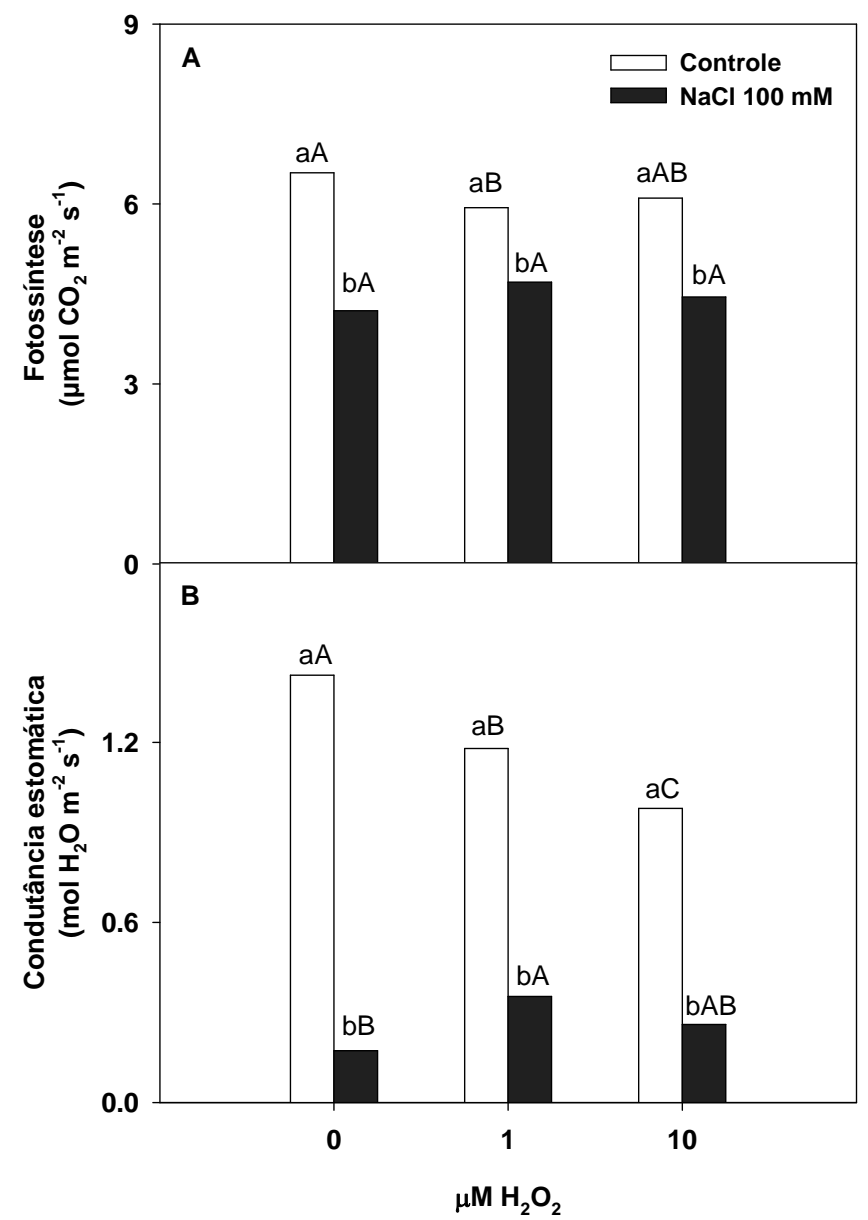

Obs.: Letras minúsculas iguais entre os níveis de $\mathrm{NaCl}$ e maiúsculas iguais entre os níveis de $\mathrm{H}_{2} \mathrm{O}_{2}$ não diferem entre si pelo teste de Tukey a $5 \%$ de probabilidade

Figura 1. Taxa fotossintética (A) e condutância estomática (B) de plantas de arroz submetidas ao pré-tratamento com diferentes concentrações de $\mathrm{H}_{2} \mathrm{O}_{2}(0,1$ e $10 \mu \mathrm{M})$ e posteriormente expostas ou não ao $\mathrm{N} \mathrm{aCl}(100 \mathrm{mM})$ na solução nutritiva

O processo fotossintético constitui um dos processos primários que podem ser afetados com a imposição de situações estressantes (Chaves et al., 2009). Nas plantas superiores a captura e o armazenamento de energia luminosa que ocorrem durante a fotossíntese, são processos realizados pela associação dos pigmentos receptores de luz e do transporte de elétrons do fotossistema II (PSII) para o fotossistema I (PSI). Este processo de transferência de elétrons entre os PSII e PSI, resulta na produção de EROs e faz parte do metabolismo normal do vegetal (Foyer \& Noctor, 2000; Müller et al., 2001).

Em plantas submetidas ao estresse salino o fechamento estomático é considerado uma das respostas fisiológicas mais rápidas, em virtude da redução registrada no potencial hídrico do solo (Munns \& Tester, 2008). Em nosso estudo foram registradas reduções significativas na condutância estomática, quando as plantas estavam expostas a $100 \mathrm{mM} \mathrm{de} \mathrm{NaCl}$ isolado ou combinado com o $\mathrm{H}_{2} \mathrm{O}_{2}$ em relação ao controle (Figura 1B).
Plantas previamente submetidas a $1 \mu \mathrm{M}$ de $\mathrm{H}_{2} \mathrm{O}_{2}$ e em seguida expostas a $100 \mathrm{mM}$ de $\mathrm{NaCl}$, apresentaram elevação na condutância estomática de cerca de $105 \%$ em relação às plantas submetidas ao $\mathrm{NaCl}$ isoladamente indicando uma recuperação no movimento estomático sinalizado, possivelmente, pelo $\mathrm{H}_{2} \mathrm{O}_{2}$ exógeno. As plantas tratadas com $10 \mu \mathrm{M}$ de $\mathrm{H}_{2} \mathrm{O}_{2}$ e em seguida submetidas ao $\mathrm{NaCl}$, também apresentaram condutância estomática superior à registrado para as plantas expostas isoladamente ao $\mathrm{NaCl}$ (Figura 1B).

A restrição do crescimento e da produtividade das plantas é um dos principais efeitos da salinidade sobre o desempenho das culturas e está associada à restrição, tanto estomática quanto não estomática, do processo fotossintético (Foyer \& Noctor, 2000). As perturbações causadas ao processo fotossintético em plantas sob condições estressantes, levam a uma produção excessiva de EROs e na ausência de mecanismos eficientes de proteção (enzimáticos ou não) podem ocorrer alterações metabólicas que resultam em danos oxidativos (Pan et al., 2006). A pré-exposição de plantas a estresses moderados ou a metabólitos sinalizadores tais como $\mathrm{oH}_{2} \mathrm{O}_{2}$, pode resultar numa sinalização metabólica na célula (aumento metabólitos e/ou enzimas antioxidativas) e, portanto, resultar num melhor desempenho fisiológico, quando a planta é exposta a condições de estresse mais severo (Veal et al., 2007; Forman et al., 2010).

As EROs resultantes do estresse severo podem ocasionar a peroxidação lipídica, danos nas membranas celulares, degradação de proteínas, quebra da dupla fita do DNA e, ainda, resultar na morte celular (Apel \& Hirt, 2004; Elkahoui et al., 2004; Møller et al., 2007; Nguyen et al., 2009). Como esperado, foram registradas elevações no percentual de dano de membrana em plantas expostas isoladamente a $100 \mathrm{mM}$ de $\mathrm{NaCl}$ (Figura 2A). Entretanto, quando as plantas foram previamente tratadas com 1 ou $10 \mu \mathrm{M}$ de $\mathrm{H}_{2} \mathrm{O}_{2}$ a elevação no dano de membrana foi inferior quando se comparada com os resultados obtidos nas plantas expostas apenas ao $\mathrm{NaCl}$ (Figura 2A).

$\mathrm{O}$ estresse oxidativo induzido pela salinidade pode causar intensa peroxidação lipídica (Hernandez \& Almansa, 2002); entretanto, a intensidade dos danos oxidativos pode variar a depender de qual rápida é a proteção oxidativa (Munns \&Tester, 2008). Neste estudo, o nível de peroxidação de lipídeos foi elevado nas plantas submetidas ao $\mathrm{NaCl}$ a $100 \mathrm{mM}$ isoladamente (sem pré-tratamento) na ordem de $27 \%$ em relação ao tratamento controle (Figura 2B). Quando as plantas receberam o pré-tratamento com $1 \mu \mathrm{M}$ de $\mathrm{H}_{2} \mathrm{O}_{2}$, registrou-se um nível menor na peroxidação de lipídeos (na ordem de 14\%) em relação ao tratamento controle.

As plantas pré-tratadas com $10 \mu \mathrm{M}$ de $\mathrm{H}_{2} \mathrm{O}_{2}$ e expostas ou não ao $\mathrm{NaCl}$, apresentaram níveis elevados de peroxidação de lipídeos (Figura 2B) indicando que este nível de $\mathrm{H}_{2} \mathrm{O}_{2}$ foi muito elevado e levando a danos aos lipídeos de membrana e não a uma prévia aclimatação. Segundo Apel \& Hirt (2004), os ácidos graxos poli-insaturados dos lipídeos são o alvo das EROs que geram radicais derivados que, por sua vez podem desempenhar papel de mensageiros secundários.

O nível de $\mathrm{H}_{2} \mathrm{O}_{2}$ nas folhas das plantas expostas ao $\mathrm{NaCl}$ isoladamente foi elevado em cerca de $25 \%$ em relação ao tratamento controle (Figura 2C). Nas plantas submetidas a salinidade, o pré-tratamento com $\mathrm{H}_{2} \mathrm{O}_{2}$ resultou em reduções 


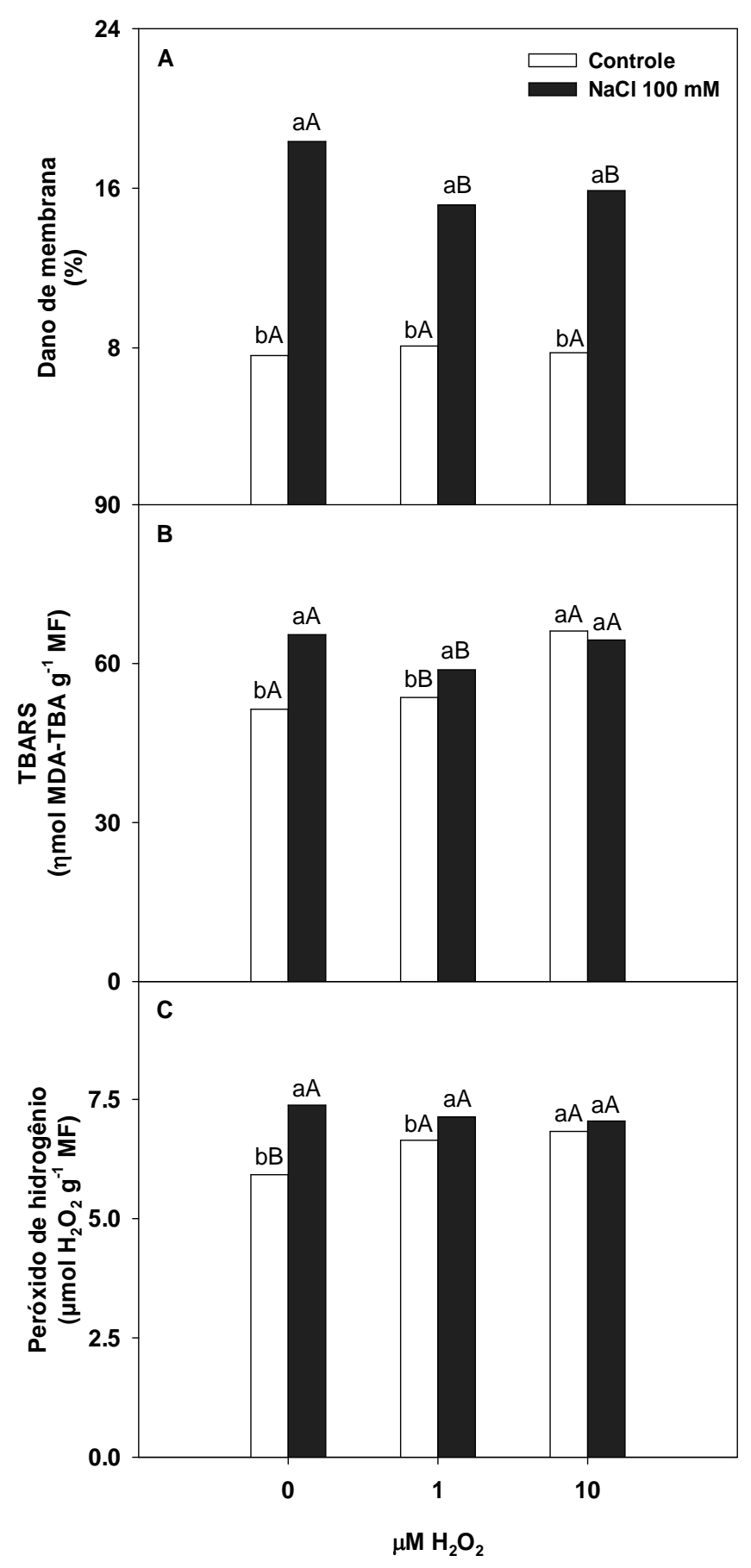

Obs.: Letras minúsculas iguais entre os níveis de $\mathrm{NaCl}$ e maiúsculas iguais entre os níveis de $\mathrm{H}_{2} \mathrm{O}_{2}$ não diferem entre si pelo teste de Tukey a $5 \%$ de probabilidade

Figura 2. Dano de membrana (A), nível de TBARS (B) e conteúdo de $\mathrm{H}_{2} \mathrm{O}_{2}$ (C) em folhas de plantas de arroz submetidas ao pré-tratamento com diferentes concentrações de $\mathrm{H}_{2} \mathrm{O}_{2}(0,1$ e $10 \mu \mathrm{M})$ e posteriormente expostas ou não ao $\mathrm{N} \mathrm{aCl}(100 \mathrm{mM})$ na solução nutritiva

mínimas no conteúdo de $\mathrm{H}_{2} \mathrm{O}_{2}$ no tecido vegetal em relação às plantas que não foram pré-tratadas (Figura 2C). $\mathrm{O} \mathrm{H}_{2} \mathrm{O}_{2}$ é uma molécula não-polar e capaz de se difundir através das membranas celulares (Veal et al., 2007); desta forma, se esperava que as plantas pré-tratadas com o $\mathrm{H}_{2} \mathrm{O}_{2}$ apresentassem uma elevação de seu conteúdo nos tecidos estudados. Quando se observou a Figura 2C, notou-se que as plantas pré-tratadas com 1 ou $10 \mu \mathrm{M}$ de $\mathrm{H}_{2} \mathrm{O}_{2}$ não apresentaram diferenças significativas no conteúdo desta molécula em seus tecidos, quando na ausência ou presença do $\mathrm{NaCl}$.

Os mecanismos de remoção de EROs podem ser enzimáticos ou não enzimáticos (Apel \& Hirt, 2004). O sistema antioxidativo enzimático é constituído principalmente pelas enzimas dismutase de superóxido (SOD), catalase (CAT), peroxidase de ascorbato (APX), redutase de glutationa (GR), redutase de monodehidroascorbato (MDHAR) e redutase de dehidroascorbato (DHAR), enquanto o sistema não enzimático é constituído sobretudo por componentes hidrofílicos, tais como o ascorbato e a glutationa. Esses componentes do sistema antioxidativo são amplamente distribuídos pela célula e atuam de forma coordenada para conferir proteção oxidativa (Foyer \& Noctor, 2003; Møller et al., 2007).

As APX são as principais peroxidases na remoção do $\mathrm{H}_{2} \mathrm{O}_{2}$ no interior da célula e atuam em sincronia com outras enzimas que participam do ciclo ascorbato-glutationa (Foyer \& Noctor, 2000). Neste estudo ocorreu redução na atividade de APX nas plantas expostas ao $\mathrm{NaCl}$ em relação ao tratamento controle em cerca de $15 \%$ (Figura $3 \mathrm{~A}$ ). As plantas previamente expostas a $1 \mu \mathrm{M}$ de $\mathrm{H}_{2} \mathrm{O}_{2}$ apresentaram elevação na atividade de APX em aproximadamente $20 \%$ em comparação com o tratamento controle, entretanto quando $10 \mu \mathrm{M}$ de $\mathrm{H}_{2} \mathrm{O}_{2}$ foram aplicados como pré-tratamento, a atividade da APX foi reduzida a níveis bastante inferiores aos do tratamento controle (Figura 3A).

Sabe-se que APX e CAT apresentam diferentes mecanismos de metabolizar $\mathrm{o}_{2} \mathrm{O}_{2}$ e que tais enzimas atuam em diferentes partes da célula vegetal (Foyer \& Noctor, 2003; Mittler et al., 2004; Kotchoni \& Gachomo, 2006; Rosa et al., 2010). Apesar de atuarem degradando o mesmo substrato, a APX e CAT apresentam diferenças de afinidade pelo $\mathrm{H}_{2} \mathrm{O}_{2}$ e esta especificidade pode ser um aspecto fundamental para provocar a modulação no nível de $\mathrm{H}_{2} \mathrm{O}_{2}$ que resultaria em sinalização e, consequentemente, proteção oxidativa (Shigeoka et al., 2002; Scandalios, 2002; 2005). Assim, o balanço entre elas a nível gênico e bioquímico, pode ser um importante mecanismo para ativar as demais rotas de defesa ao estresse oxidativo, frente a condições de estresses ambientais (Møller et al., 2007; Nguyen et al., 2009).

A CAT é uma enzima tetramérica, que contém um grupo heme-protéico em cada subunidade e converte $\mathrm{o}_{2} \mathrm{O}_{2} \mathrm{em} \mathrm{H}_{2} \mathrm{O}$ e $\mathrm{O}_{2}$ (Møller, 2001; Horváth et al., 2002). Esta enzima se encontra localizada nos peroxissomos e/ou glioxissomos e não é encontrada nos cloroplastos (Scandalios, 2005). Devido a CAT apresentar menor afinidade pelo $\mathrm{H}_{2} \mathrm{O}_{2}$, quando comparada com a APX, ela é considerada essencial na remoção de $\mathrm{H}_{2} \mathrm{O}_{2}$ oriundo da fotorrespiração (Foyer \& Noctor, 2000).

Em nosso estudo a atividade de CAT apresentou-se reduzida quando as plantas foram expostas ao $\mathrm{NaCl}$, mesmo quando houve o pré-tratamento com $\mathrm{H}_{2} \mathrm{O}_{2}$ (Figura 3B); entretanto, a exposição previa das plantas a $1 \mu \mathrm{M}$ de $\mathrm{H}_{2} \mathrm{O}_{2}$, combinadas com posterior exposição ao $\mathrm{NaCl}$ resultou no aumento da atividade de CAT de aproximadamente $40 \%$ em relação às plantas expostas ao $\mathrm{NaCl}$ sem pré-tratamento. Quando o pré-tratamento foi feito com $10 \mu \mathrm{M}$ de $\mathrm{H}_{2} \mathrm{O}_{2}$, pôde-se registrar que a atividade de CAT não foi estimulada, indicando que o $\mathrm{H}_{2} \mathrm{O}_{2}$ exógeno nesta concentração não foi eficiente para ocasionar uma 


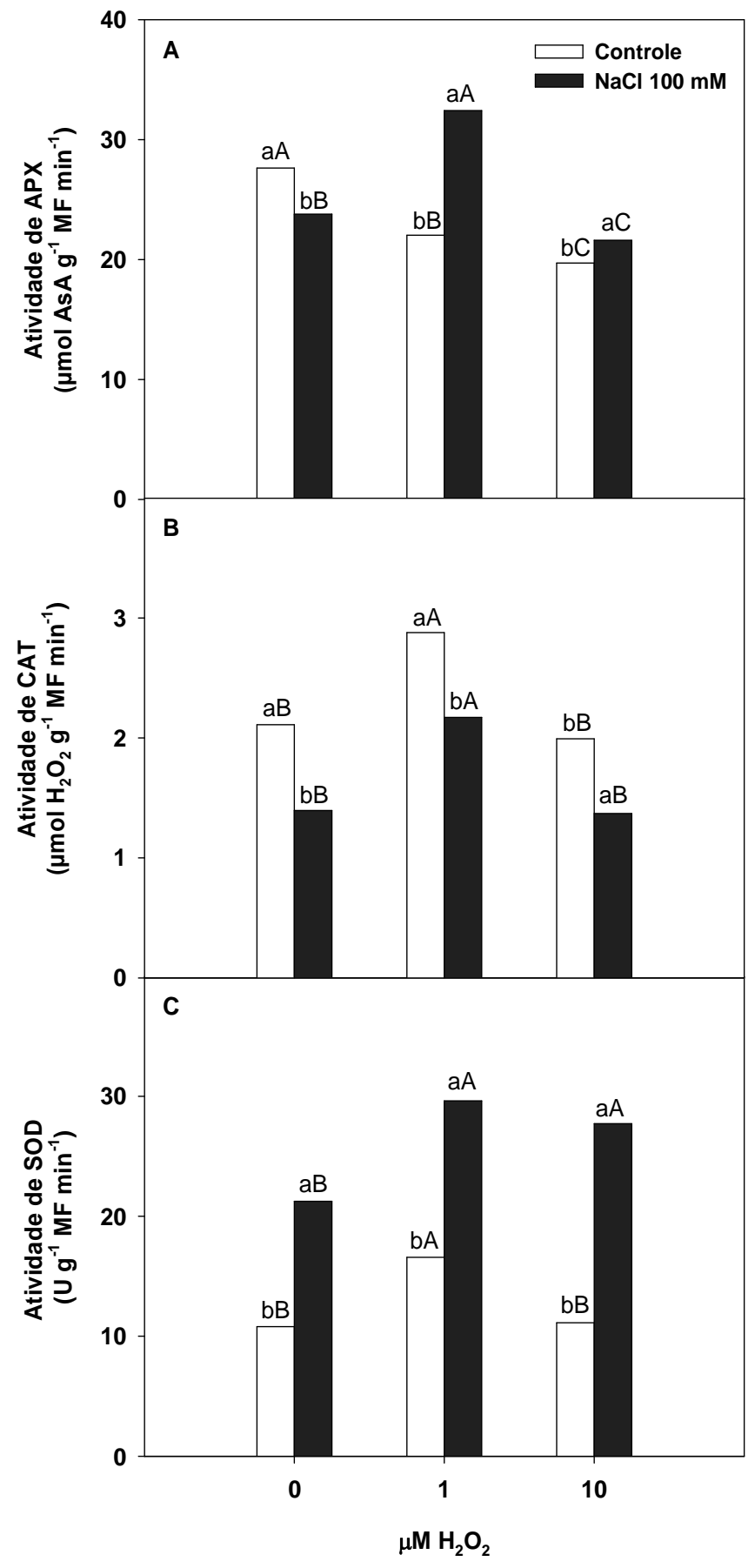

Obs.: Letras minúsculas iguais entre os níveis de $\mathrm{NaCl}$ e maiúsculas iguais entre os níveis de $\mathrm{H}_{2} \mathrm{O}_{2}$ não diferem entre si pelo teste de Tukey a $5 \%$ de probabilidade

Figura 3. Atividade das enzimas Ascorbato peroxidase (A), Catalase (C) e Dismutase do superóxido (C) em folhas de plantas de arroz submetidas ao pré-tratamento com diferentes concentrações de $\mathrm{H}_{2} \mathrm{O}_{2}(0,1$ e $10 \mu \mathrm{M})$ e posteriormente expostas ou não ao $\mathrm{N} \mathrm{aCl}(100 \mathrm{mM})$ na solução nutritiva

sinalização previa celular que levasse ao aumento da expressão de genes/proteínas de CAT.

A atividade de SOD apresentou-se elevada tanto nas plantas expostas ao $\mathrm{NaCl}$ isolado quanto naquelas pré-tratadas com 1 ou $10 \mu \mathrm{M}$ de $\mathrm{H}_{2} \mathrm{O}_{2}$ (Figura 3C). A SOD é uma metaloenzima possível de ser classificada de acordo com seu cofator metálico ( $\mathrm{Mn}, \mathrm{Fe}$, ou $\mathrm{Cu}-\mathrm{Zn}$ ) e encontrada em todos os compartimentos capazes de produzir EROs, particularmente em cloroplastos, mitocôndria e peroxissomos (Moran et al., 2003; Cavalcanti et al., 2004). É responsável pela dismutação do superóxido $\left(\mathrm{O}_{2}^{*}\right)$ para $\mathrm{H}_{2} \mathrm{O}_{2}$ e oxigênio molecular, sendo considerada a primeira linha de defesa oxidativa enzimática dentro da célula vegetal (Foyer \& Noctor, 2000; Xiong \& Zhu, 2001). Alguns autores relatam uma modulação positiva na atividade de SOD, resultante na exposição ao estresse salino e esta resposta poderia estar relacionada a uma tolerância maior a situações de estresse (Vaidyanathan et al., 2003; Demiral \& Turkan, 2005; Koca et al., 2006; Hu et al., 2008; Ryang et al., 2009).

\section{ConClus Ão}

1. A partir dos dados apresentados foi possível concluir que baixas doses de $\mathrm{H}_{2} \mathrm{O}_{2}$ são suficientes para induzir os sistemas de defesa antioxidativos, de modo a minimizar os efeitos deletérios da salinidade. Entretanto, mais estudos são necessários para se entender como esses mecanismos são ativados e desencadeados dentro da célula vegetal.

\section{LITERATURA CITADA}

Apel, K.; Hirt, H. Reactive oxygen species: Metabolism, oxidative stress, and signal transduction. Annual Review Plant Biotechnology, v.55, p.373-399, 2004.

Arora, A.; Sairam, R. K.; Srivastava, G. C. Oxidative stress and antioxidative system in plants. Current Science, v.82, p.12271238, 2002.

Beauchamp, C.; Fridovich, I. Superoxide dismutase: Improved assaysand an assay applicable to acrylamide gels. Anal Biochemistry, v.44, p.276-287, 1971.

Brennan, T.; Frenkel, C. Involvement of hydrogen peroxide the regulation of senescence in pear. Plant Physiology, v.59, p.411-416, 1977.

Camp, R. G. L.; Przybyla, D.; Ochsenbein, C.; Laloi, C.; Kim, C.; Chen, H. X.; Gao, H. Y.; An, S. Z.; Li, J. Dissipation of excess energy in Mehler-peroxidase reaction in Rumex leaves during salt shock. Photosynthetica, v.42, p.117-122, 2004.

Cattivelli, L.; Rizza, F.; Badeck, F. W.; Mazzucotelli, E.; Mastrangelo, A. M.; Francia, E.; Maré, C.; Tondelli, A.; Stanca, A. M. Drought tolerance improvement in crop plants: An integrated view from breeding to genomics. Field Crops Research, v.105, p.1-14, 2008.

Cavalcanti, F. R.; Oliveira, J. T. A.; Martins-Miranda, A. S.; Viegas, R. A.; Silveira, J. A. G. Superoxide dismutase, catalase and peroxidase activities do not confer protection against oxidative damage in salt-stressed cowpea leaves. New Phytologist, v.163, p.563-571, 2004.

Chaves, M. M.; Flexas, J.; Pinheiro, C. Photosynthesis and salt stress: Regulation mechanisms from whole plant to cell. Annals of Botany, v.103, p.551-560, 2009.

Demiral, T.; Turkan, I. Comparative lipid peroxidation, antioxidant defense system and proline content in roots of two rice cultivars differing in salt tolerance. Environmental and Experimental Botany, v.53, p.247-257, 2005. 
Elkahoui, S.; Smaoui, A.; Zarrouk, M.; Ghrir; R.; Limam, F. Saltinduced lipid changes in Catharanthus roseus cultured cell suspensions. Phytochemistry, v.65, p.1911-1917, 2004.

El-Shabrawi, H.; Kumar, B.; Kaul, T.; Reddy, M. K.; Silngla-Pareek, S. L.; Sopory, S. K. Redox homeostasis, antioxidant defense, and methylglyoxal detoxification as markers for salt tolerance in Pokkali rice. Protoplasma, v.245, p.85-96, 2010.

Forman, H. J.; Maiorino, M.; Ursini, F. Signaling functions of reactive oxygen species. Biochemistry, v.49, p.835-842, 2010.

Foyer, C. H.; Noctor, G. Oxygen processing in photosynthesis: Regulation and signaling. New Phytologist, v.146, p.359-388, 2000.

Foyer, C. H.; Noctor, G. Redox sensing and signaling associated with reactive oxygen in chloroplasts, peroxisomes and mitochondria. Physiologia Plantarum, v.119, p.355-364, 2003.

Giannopolotis, C. N.; Ries, S. K. Superoxide dismutases: I. Occurrence in Higher Plants. Plant Physiology, v.59, p.309314, 1977.

Guo, Y. P.; Zhou, H. F.; Zhang, L. C. Photosynthetic characteristics and protective mechanisms against photoxidation during high temperature stress in two citrus species. Scientia Horticulturae, v.108, p.260-267, 2006.

Havir, E. A.; McHale, N. A. Biochemical and developmental characterization of multiple forms of catalase in tobaccoleaves. Plant Physiology, v.84, p.450-455, 1987.

Heath, R. L.; Packer, L. Photoperoxidation in isolated chloroplasts. I. Kinetics and Stoichiometry of fatty acid peroxidation. Archives of Biochemistry and Biophysics, v.125, p.189-198, 1968.

Hernandez, J. A.; Almansa, M. S. Short-term effects of salt stress on antioxidant systems and leaf water relations of pea leaves. Physiologia Plantarum, v.115, p.251-257, 2002.

Horváth, E.; Janda, T.; Szalai, G.; Páldi, E. In vitro salicylic acid inhibition of catalase activity in maize: differences between the isoenzymes and a possible role in the induction of chilling tolerance. Plant Science, v.163, p.1129-1135, 2002.

Hu, W. H.; Song, X. S.; Shi, K.; Xia, X. J.; Zhou, Y. H.; Yu, J. Q. Changes in electron transport, superoxide dismutase and ascorbate peroxidase isoenzymes in chloroplasts and mitochondria of cucumber leaves as influenced by chilling. Photosynthetica, v.46, p.581-588, 2008.

Koca, H.; Ozdemir, F.; Turkan, I. Effect of salt stress on lipid peroxidation and superoxide dismutase and peroxidase activities of Lycopersicon esculentum and L. pennellii. Biologia Plantarum, v.50, p.745-748, 2006.

Kotchoni, S. O.; Gachomo, E. W. The reactive oxygen species network pathways: an essential prerequisite for perception of pathogen attack and the acquired disease resistance in plants. Journal of Bioscience, v.31, p.389-404, 2006.

Mahajan, S.; Tuteja, N. Cold, salinity and drought stresses: An overview. Archives of Biochemistry and Biophysics, v.444, p.139-158, 2005.

Miller, G.; Shulaev, V.; Mittler, R. Reactive oxygen signaling and abiotic stress. Physiologia Plantarum, v.133, p.481-489, 2008.

Miller, G.; Suzuki, N.; Ciftci-Yilmaz, S.; Mittler, R. Reactive oxygen species homeostasis and signalling during drought and salinity stresses. Plant, Cell and Environment, v.33, p.453$467,2010$.
Mittler, R. Oxidative stress, antioxidants and stress tolerance. Trends in Plant Science, v.7, p.405-410, 2002.

Mittler, R.; Vanderauwera, S.; Gollery, M.; van Breusegem, F. Reactive oxygen gene network of plants. Trends in Plant Science, v.9, p.490-498, 2004.

Møller, I. M. Plant mitochondria and oxidative stress: Electron transport, NADPH turnover, and metabolism of reactive oxygen species. Annual Review Plant Physiology and Plant Molecular Biology v.52, p.561-591, 2001.

Møller, I. M.; Jénsen, P. E.; Hansson, A. Oxidative Modifications to cellular components in plants. Annual Review of Plant Biology, v.58, p.459-81, 2007.

Moran, J. F.; James, E. K.; Rubio, M. C.; Sarath, G.; Klucas, R. V.; Becana, M. Functional characterization and expression of a cytosolic iron-superoxide dismutase from Cowpea root nodules. Plant Physiology v.133, p.773-782, 2003.

Müller, P.; Li, X. P.; Niyogi, K. K. Non-photochemical quenching. A response to excess light energy. Plant Physiology, v.125, p.1558-1566, 2001.

Munns, R.; Tester, M. Mechanisms of salinity tolerance. Annual Review of Plant Biology, v.59, p.651-681, 2008.

Nakano, Y.; Asada, K. Hydrogen peroxide is scavenged by ascorbate-specific peroxidase in spinach chloroplasts. Plant Cell Physiology, v.22, p.1068-1072, 1981.

Nguyen, G. N.; Hailstones, D. L.; Wilkes, M.; Sutton, B. G. Drought-induced oxidative conditions in rice anthers leading to a programmed cell death and pollen abortion. Journal of Agronomy \& Crop Science, v.195, p.157-164, 2009.

Pan, Y.; Wu, L. J.; Yu, Z. L. Effect of salt and drought stress on antioxidant enzymes activities and SOD isoenzymes of liquorice (Glycyrrhiza uralensis Fisch). Plant Growth Regulation, v.49, p.157-165, 2006.

Rosa, S. B.; Caverzan, A.; Teixeira, F. K.; Lazzarotto, F.; Silveira, J. A. G.; Ferreira-Silva, S. L.; Abreu Neto, J.; Margis, R.; Margis-Pinheiro, M. Cytosolic APx knockdown indicates an ambiguous redox responses in rice. Phytochemistry, v.71, p.548-558, 2010.

Ryang, S.; Woo, S.; Kwon, S.; Kim, S.; Lee, S. H.; Kim, K.; Lee, D. Changes of net photosynthesis, antioxidant enzyme activities, and antioxidant contents of Liriodendron tulipifera under elevated ozone. Photosynthetica, v.47, p.19-25. 2009.

Scandalios, J. G. The rise of ROS. Trends in Biochemical Sciences, v.27, p.483-486, 2002.

Scandalios, J. G. Oxidative stress: Molecular perception and transduction of signals triggering antioxidant gene defenses. Brazilian Journal of Medical and Biological Research, v.38, p.995-1014, 2005.

Shigeoka, S.; Ishikawa, T.; Tamoi, M.; Miyagawa, Y.; Takeda, T.; Yabuta, Y.; Yoshimura, K. Regulation and function of ascorbate peroxidase isoenzymes. Journal of Experimental Botany, v.53, p.1305-19, 2002.

Vaidyanathan, H.; Sivakumar, P.; Chakrabarty, R.; Thomas, G. Scavenging of reactive oxygen species in $\mathrm{NaCl}$-stressed rice (Oryza sativa L.) - Differential response in salt-tolerant and sensitive varieties. Plant Science, v.165, p.1411-1418, 2003. 
Veal, E. A.; Day, A. M.; Morgan, B. A. Hydrogen peroxide sensing and signaling. Molecular Cell, v.26, p.1-4, 2007.

Xiong, L.; Schumaker, K. S.; Zhu, J. K. Cell Signaling during cold, drought, and salt stress. The Plant Cell, v.14, p.S165S183, 2002 .
Xiong, L.; Zhu, J. K. Abiotic stress signal transduction in plants: Molecular and genetic perspectives. Physiologia Plantarum, v.112, p.152-166, 2001.

Zimmermam, P.; Heinlein, C.; Orendi, G; Zentgra, U. Senescencespecific regulation of catalases in Arabidopsis thaliana (L.) Heynh. Plant, Cell and Environment, v.29, p.1049-1060, 2006. 